\title{
Efficacy of essential oils against Varroa destructor infesting Apis mellifera Linn. colonies and their impact on brood development
}

\author{
Vimla Goswami*, Poonam Srivastava and M. S. Khan \\ Pantnagar-263145 (Uttarakhand), INDIA \\ *Corresponding author. E-mail: vimlagoswami87@yahoo.co.in \\ Received: December 4, 2013; Revised received: February 7, 2014; Accepted: February 15, 2014
}

Department of Entomology, College of Agriculture, G.B. Pant University of Agriculture and Technology

\begin{abstract}
Varroa destructor is a dangerous pest directly for beekeeping and indirectly for crops that require insect pollination. The present investigation has been carried out to study the efficacy and persistence of some essential oils and formic acid against Varroa mite in colonies of Apis mellifera Linn. at Pantnagar, Uttarakhand. The results revealed that highest mite mortality $(77.54 \%)$ with highest brood development $(21.74 \%$ increase) recorded in garlic oil followed by turmeric oil $(75.84 \%)$ with 15.39 per cent increases in brood development. The hives treated with $T_{1}$ (tulsi oil), $T_{3}$ (turmeric oil), $T_{4}$ (ajwin oil), $T_{5}$ (cinnamon oil), $T_{5}$ (clove oil) and $T_{7}$ (formic acid) also showed good persistence with mite mortality ranging from 66.54 to $77.54 \%$ and brood development -3.12 to 21.74 per cent increase after 3 weeks exposure of the treatments.
\end{abstract}

Keywords: Apis mellifera, Varroa mite, Essential oils, Formic acid

\section{INTRODUCTION}

The honey bee, Apis mellifera L., is critical for crop pollination and honey production.The mites (Acari) that parasitize honey bees have become a global problem. They are threatening the survival of managed and feral honey bees, the beekeeping industry and, due to the role of bees in pollination, the future of many agricultural crops. Varroa destructor (Anderson and Trueman, 2000) formerly named V. jacobsoni Oudemans is potentially the main parasite of Apis mellifera L. and it can cause the collapse of untreated colonies in a few years. This mite which feeds on haemolymph of brood and adult bees causes colony disorder, weakness, decrease in brood and deformation of bees. It also reduces colony ability to pollinate plants (De Jong et al., 1984). The parasite destroys the mechanical protective barriers of the integument and impairs the immune system of the bees (Glinski, 1991). The varroa mite has been a threat to world beekeeping industry and now a potential threat to Indian apiculture (Gatoria et al., 2004).

Several chemical substances were used successfully to control mites, and a wide array of chemicals were highly effective, killing more than $99 \%$ of the mites present in infested colonies (Ferrer-Dufol et al., 1991). In recent years, resistance to acaricides has become a major problem in the control of Varroa. Increased tolerance to the most widely used synthetic active ingredients has been observed. $V$. destructor strains have been reported to be resistant to fluvalinate and flumethrin (Baxter et al., 1998), coumaphos (Spreafico et al., 2001), and to amitraz (Elzen et al., 2000). Also, the use of acaricides should be minimized in beekeeping because of the residues and their breakdown products in honey and wax (Wallner, 1999). There is current concern about contamination of bee products with synthetic substances against the varroa (Howis and Nowakowski, 2009). The problems associated with the use of acaricides proved considerable incentive to develop new treatment strategies and screening for potential acaricides that minimize these problems. Natural products having components with various modes of action might provide effective solution to the problem of Varroaosis (Imdorf et al., 1999). These natural products such as essential oils and their components or organic acids, especially formic acid, oxalic acid and citric acid were used for controlling varroa mites (Mutinelli et al., 1997).

Keeping in view of the serious threat of Varroa mite in the beekeeping and several constraints for its control the present investigation was carried out to develop the safe and effective management option for the mite population. The present investigation is aimed to determine the effective control of varroa mite by using some essential oils and compared with widely used acaricide, formic acid in the hive of A. mellifera colonies.

\section{MATERIALS AND METHODS}

The field experiments were conducted during 2012 at Apiary, Department of Entomology College of 
Agriculture, Govind Ballabh Pant University of Agriculture and Technology, Pantnagar (Utttarakhand).

For conducting this experiment, in total six oils (Tulsi oil, Garlic oil, Turmeric oil, Ajwin oil, Cinnamon oil and Clove oil) along with formic acid were used for testing their efficacy against varroa mite. The experiment was conducted with 8 treatments (including formic acid and untreated control) replicated three times. Before treatment all the cracks and crevices in the hive were plugged with mud. A thick white paper sheet was placed on the bottom board beneath the frames. In each treatment, two stirps of absorbent cotton pad ( $3 \times 2$ inches each) were soaked in equal quantity of $5 \mathrm{ml}$ for $24 \mathrm{hrs}$ at placed at bottom of hive near to brood @ 2 strips per colony. Each treatment was repeated after seven days of interval and observations were taken daily from one day after treatment to twenty one day by counting the fallen dead mite on white sheet and sheet was changed daily. Data gathered during the experiment, such as the number of dead mites that had mites on the white paper sheet at the bottom of the hives was used to determine mite mortality. The data collected from experiments were statistically analyzed. The randomized block design was used to find out the efficacy of different essential oils against the mite, $V$. destructor.

Percent mite mortality in honey bee colonies was calculated by using following formula

Table 1. Effect of different essential oils and formic acid against $V$. destructor mortality applied on absorbent cotton pad in $A$. mellifera colonies during 2012.

\begin{tabular}{llcccc}
\hline Treatment & Compounds & \multicolumn{4}{c}{ Average number of dead/fallen mite/ hive } \\
\cline { 3 - 6 } & & $\begin{array}{c}\text { Pre treatment } \\
\text { count }\end{array}$ & $\begin{array}{c}\text { After one } \\
\text { week treatment }\end{array}$ & $\begin{array}{c}\text { After two week } \\
\text { treatment }\end{array}$ & $\begin{array}{c}\text { After three } \\
\text { week treatment }\end{array}$ \\
\hline $\mathrm{T}_{1}$ & Tulsi oil & $12.32(2.12)^{*}$ & $19.56(2.53)$ & $16.32(2.43)$ & $11.65(2.01)$ \\
$\mathrm{T}_{2}$ & Garlic oil & $14.00(2.27)$ & $25.00(2.94)$ & $22.67(2.75)$ & $18.66(2.57)$ \\
$\mathrm{T}_{3}$ & Turmeric oil & $13.41(2.22)$ & $22.67(2.75)$ & $21.00(2.56)$ & $16.20(2.42)$ \\
$\mathrm{T}_{4}$ & Ajwain oil & $15.12(2.35)$ & $16.89(2.46)$ & $15.43(2.37)$ & $8.99(1.83)$ \\
$\mathrm{T}_{5}$ & Cinnamon oil & $13.22(2.20)$ & $19.44(2.51)$ & $17.22(2.48)$ & $15.10(2.35)$ \\
$\mathrm{T}_{6}$ & Clove oil & $11.00(1.97)$ & $20.43(2.57)$ & $17.76(2.52)$ & $15.65(2.39)$ \\
$\mathrm{T}_{7}$ & Formic acid & $11.11(1.98)$ & $25.33(2.96)$ & $22.34(2.72)$ & $16.00(2.41)$ \\
$\mathrm{T}_{8}$ & Control & $9.00(1.85)$ & $6.44(1.62)$ & $6.30(1.61)$ & $6.33(1.61)$ \\
\hline & SEM \pm & $\mathbf{0 . 7 5 ( 0 . 1 9 )}$ & $\mathbf{2 . 0 2 ( 0 . 4 2 )}$ & $\mathbf{1 . 6 3 ( 0 . 3 4 )}$ & $\mathbf{0 . 6 6}(\mathbf{0 . 1 6})$ \\
\hline & CD at 5\% & $\mathbf{2 . 2 8}(\mathbf{0 . 6 0})$ & $\mathbf{6 . 1 4}(\mathbf{1 . 2 7})$ & $\mathbf{4 . 9 5 ( 1 . 0 3 )}$ & $\mathbf{2 . 0 2 ( 0 . 4 9 )}$ \\
\hline
\end{tabular}

*Data given in parentheses are square root transformed values

Table 2. Efficacy and persistence of essential oils and formic acid on the per cent mortality of Varroa mite, V. destructor in A. mellifera colonies during 2012.

\begin{tabular}{llcccc}
\hline Treatment & Compounds & \multicolumn{4}{c}{ \% mite mortality } \\
\cline { 3 - 6 } & & $\begin{array}{c}\text { After one } \\
\text { week treatment }\end{array}$ & $\begin{array}{c}\text { After two week } \\
\text { treatment }\end{array}$ & $\begin{array}{c}\text { After three week } \\
\text { treatment }\end{array}$ & Mean \\
\hline $\mathrm{T}_{1}$ & Tulsi oil & $75.23(27.47)^{*}$ & $72.14(25.87)$ & $69.96(27.27)$ & 72.44 \\
$\mathrm{~T}_{2}$ & Garlic oil & $79.76(29.12)$ & $78.90(28.61)$ & $74.66(27.12)$ & 77.54 \\
$\mathrm{~T}_{3}$ & Turmeric oil & $78.71(28.78)$ & $76.93(28.15)$ & $71.90(25.70)$ & 75.84 \\
$\mathrm{~T}_{4}$ & Ajwain oil & $70.11(27.32)$ & $70.84(27.55)$ & $58.64(24.92)$ & 66.54 \\
$\mathrm{~T}_{5}$ & Cinnamon oil & $75.11(27.75)$ & $73.21(26.50)$ & $70.46(25.05)$ & 72.92 \\
$\mathrm{~T}_{6}$ & Clove oil & $76.00(27.79)$ & $73.88(26.85)$ & $71.20(25.95)$ & 73.69 \\
$\mathrm{~T}_{7}$ & Formic acid & $79.79(29.12)$ & $79.72(28.81)$ & $71.65(25.52)$ & 76.72 \\
$\mathrm{~T}_{8}$ & Control & $0.00(0.00)$ & $0.00(0.00)$ & $0.00(0.00)$ & 0.00 \\
\hline SEM \pm & & $\mathbf{3 . 3 4}(\mathbf{1 . 2 7})$ & $\mathbf{2 . 4 4 ( 1 . 1 8 )}$ & $\mathbf{1 . 9 4}(\mathbf{0 . 9 4})$ & $\mathbf{1 . 6 4}$ \\
\hline CD at 5\% & & $\mathbf{8 . 0 2 ( 7 . 3 2 )}$ & $\mathbf{7 . 5 2}(\mathbf{6 . 9 2})$ & $\mathbf{1 5 . 3 5}(\mathbf{1 3 . 1 7})$ & $\mathbf{1 0 . 4 0}$ \\
\hline
\end{tabular}

*Data given in parentheses are square root transformed values 


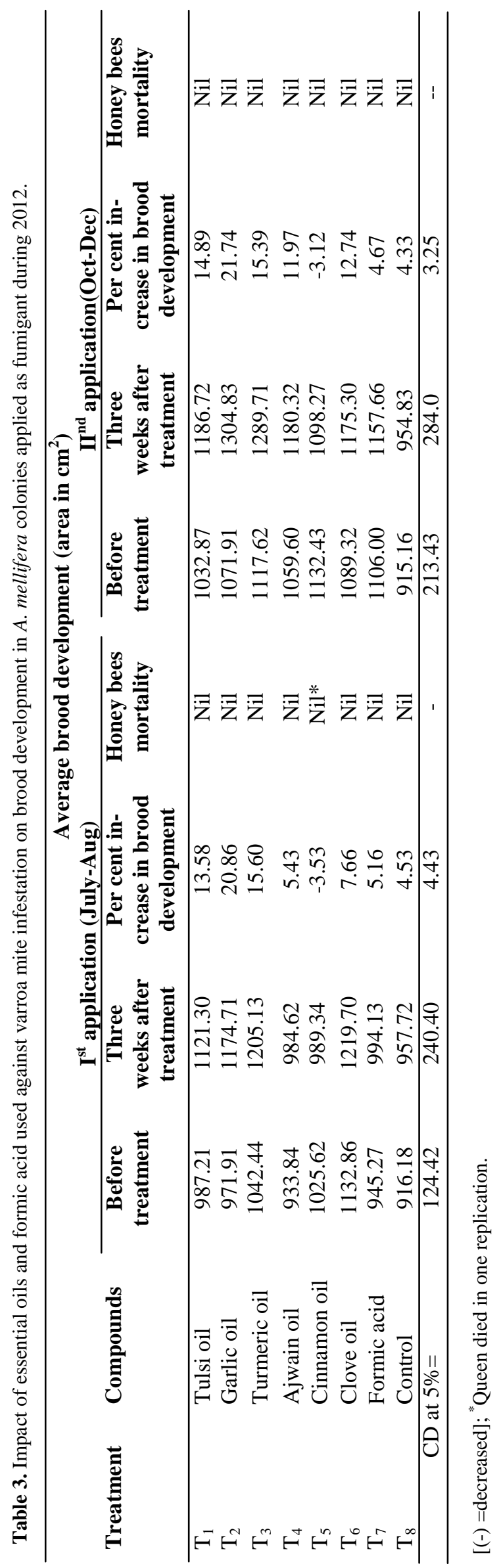

$\%$ mite mortality $=$ Mite mortality in treatment $/$ (Mite mortality in treatment + Mite mortality in control) $\mathrm{X}$ 100

The effect of essential oils on brood development in $A$. mellifera colonies, brood measurement was done before and after 5 days of each treatment. Measurement of brood was done with the help of scale. Both the side of the frame in hive having brood was measured with the help of scale. Percent change in brood development in honey bee colonies was calculated by, using following formula

$\%$ change in brood development $=($ Final brood Initial brood / Initial brood) X 100

\section{RESULTS AND DISCUSSION}

The efficacy and persistence of essential oils and formic acid were evaluated against varroa mite and number of fallen mites/hive/week, per cent mite mortality and their impact on brood development are summarized in tables 1, 2 and 3 .

First week observations revealed that highest no. of dead/fallen mites per colony (25.33: 79.79\%) and $(25.00 ; 79.76 \%)$ mortality was recorded in treatment $\mathrm{T}_{7}$ (Formic acid) and $\mathrm{T}_{2}$ (garlic oil) followed by treatment $\mathrm{T}_{3}$ (turmeric oil), with from 22.67 dead / fallen mites giving $78.71 \%$ mite mortality. Both these treatments gave significantly higher mite mortality as compared to other treatments. The number of fallen mites recorded after one weeks in the treatment $\mathrm{T}_{6}$ (clove oil), $\mathrm{T}_{1}$ (tulsi oil), $\mathrm{T}_{5}$ (cinnamon oil) and $\mathrm{T}_{4}$ (ajwin oil) treated colonies were 20.43, 19.56, 19.44 and 16.89 fallen mites/hive/week with and per cent mite mortality of $78.71,76.00,75.23,75.11$ and 70.11 respectively.

The observations after second week indicated that number of fallen mites recorded in treatment $T_{7}$ (formic acid) and $\mathrm{T}_{2}$ (garlic oil) 22.34 and 22.67, dead / fallen mites / hive / week with 79.72 and 78.90 $\%$ mite mortality which were significantly higher than in $\mathrm{T}_{3}$ (turmeric oil), $\mathrm{T}_{6}$ (clove oil), $\mathrm{T}_{5}$ (cinnamon oil), $\mathrm{T}_{1}$ ( tulsi oil), and $\mathrm{T}_{4}$ (ajwin oil) treated colonies with $21.00,17.76,17.22,16.32$ and 15.43 fallen mites/ hive/week giving 76.93, 73.88, 73.21, 72.14 and 70.84 percent mite mortality, respectively. Similar pattern was observed in third week after treatments but with deceased number of fallen mites and percent mortality. Rana et al. (2010) also reported that placing formic acid sponge pads during summer months resulted in 83 $-90 \%$ mite mortality. These findings are also in line with the earlier reports of Hoppe et al. (1989) and Stangellini and Raybold (2004).

The results showed that among seven treatments applied for Varroa mite control, Garlic oil $\left(\mathrm{T}_{2}\right)$ and formic acid $\left(\mathrm{T}_{7}\right)$ treatments were significantly better. garlic oil $\left(\mathrm{T}_{2}\right)$ treatment gave highest mite mortality $(79.76 \%)$ after one week which decreased to 78.90 per cent after two weeks and then to 74.66 per cent after three weeks giving an overall mortality of 75.54 
percent with the highest brood development 20.86 per cent. This per cent increased brood development was significantly higher $(\mathrm{P}<0.005)$ than the treatments of clove oil (7.66), ajwin oil (5.43), formic acid (5.16) and untreated (4.53). During the three weeks, no queen and worker bees loss was observed.

However, in treatment $\mathrm{T}_{5}$ (cinnamon oil) after first application brood development was decreased by -3.53 per cent three weeks after treatment. This decrease in brood development was due to high mite infestation and loss of one queen in the bee colonies. Abd ElWahab et al. (2012) reported that the highest concentration of tested oils resulted in high amount of sealed worker brood particularly in anise and lemon grass oils, while, the cinnamon oil and formic acid recorded the lowest one.

It was concluded that garlic oil is effective in causing varroa mite mortality to a level of $78.90 \%$ upto two weeks and the application need repeation thereafter for achieving effective control. The effectiveness of garlic oil can be an alternative to formic acid, a chemical treatment widely being used in A. mellifera colonies against Varroa mite. The use of essential oil may fit well into Integrated Pest Management (IPM) programs for alternative use with other control measures for the management of Varroa mite and other pests in honeybee colonies although they enhance chances for colony survival and ensure residue-free hive products.

\section{REFERENCES}

Abd El-Wahab, T. E., Ebadah, I. M. A. and Zidan, E.W (2012). Control of varroa mite by essential oils and formic acid with their effects on grooming behaviour of honey bee colonies J. Basic. Appl. Sci. Res., 2 (8) 76747680.

Anderson D.L., and Trueman, J.W.H. (2000). Varroa jacobsoni (Acari: Varroidae) is more than one species. Exp. Appl. Acarol., 24:165-189.

Baxter, J., Eischen, F., Pettis, J., Wilson, W.T. and Shimanuki, H. (1998). Detection of fluvalinate-resistant Varroa mites in U.S. honeybees. Amer. Bee J., 138:291.

De Jong, D., Gonc., Alves, L.S. and Morse, R. A. (1984).
Dependence on climate of the virulence of $V$. jacobsoni. Bee World, 65: 11 7-121.

Elzen, P.J., Baxter, J.R., Spivak, M. and Wilson, W.T. (2000). Control of Varroa jacobsoni Oud. resistant to fluvalinate and amitraz using coumaphos. Apdiologie, 31:437-441.

Ferrer-Dufol, M., Martinez-Vinuales, A. I. and SanchezAcedo, C. (1991). Comparative tests of fluvalinate and flumethrin to control Varroa jacobsoni Oudemans. J. Apic. Res. 30, 103-106.

Gatoria, G. S., Chhuneja, P. K., Jaspal Singh and Blossom (2004). Varroa mite-A potential threat to the Indian Apiculture. Indian Bee Journal, 66 (3-4): 112-122.

Glinski, Z. (1991). The effect of Varroa jacobsoni Oud. on the incidence and cause of chalkbrood disease in Apis mellifera L. colonies. Rev. Agric. Entom., 079-09747.

Hoppe, H., Ritter, W. and Stephen, E. W. C. (1989). The control of parasitic bee mites: Varroa jacobsoni, Acarapis woodi and Tropilaelaps clareae with formic acid. American Bee J., 129: 739-742.

Howis, M. and Nowakowski, P. (2009). Varroa destructor removal efficiency using bee vital hive clean preparation. Journal of Apicultural Science,35(2):15-20.

Imdorf, A., Bogdanov, S., Ochoa, R. I. and Calderone, N. W. (1999). Use of essential oils for the control of Varroa jacobsoni Oud. In honey bee colonies. Apidologie 30(23): 209-228.

Mutinelli, F., Baggio. A., Capolongo, F., Piro. R., Prandin L. and Biasim, L. (1997). A scientific note on oxalic acid by topical application for the control of varroasis. Apidologie 28:461-462.

Rana, K., Sharma, H. K. and Rana, B. S. (2010). Efficacy of formic acid sponge pad against varroa destructor infesting Apis mellifera L. Indian Journal of Entomology, 72 (3): 209-211.

Spreafico, M., Eördegh. F. R., Bernardinelli, L. and Colombo, M. (2001). First detection of strains of Varroa destructor resistant to coumaphos: Results of laboratory test and field trials. Apidologie, 32:49-55.

Stanghellini, M. S. and Raybold, P. (2004). Evaluation of selected biopesticides for the late fall control of varroa mites in a northern temperate climate. American Bee Journal, 144 (6): 475-480.

Wallner, K. (1999). Varroacides and their residues in bee products. Apidologie, 30:235-248. 